\title{
Editorial
}

\section{Why a special issue of JIDC on the Structured Operational Research and Training Initiative in Armenia}

\author{
Karapet Davtyan ${ }^{1}$, Zhanna Davtyan², Gevorg Yaghjyan¹, Rony Zachariah ${ }^{3}$ \\ ${ }^{1}$ TB Research and Prevention Center NGO, Yerevan, Armenia \\ ${ }^{2}$ Ministry of Health of Armenia, Yerevan, Armenia \\ ${ }^{3}$ Special Programme for Research and Training in Tropical Diseases (WHO/TDR) hosted at the World Health \\ Organization, Geneva, Switzerland
}

Key words: operational research; infection; SORT IT.

J Infect Dev Ctries 2019; 13(5S):1S. doi:10.3855/jidc.11446

(Received 14 March 2019 - Accepted 08 April 2019)

Copyright (C) 2019 Davtyan et al. This is an open-access article distributed under the Creative Commons Attribution License, which permits unrestricted use, distribution, and reproduction in any medium, provided the original work is properly cited.

On behalf of the Editorial Board of JIDC.

The Journal of Infection in Developing Countries (JIDC) promotes operational research from low- and middle-income countries where burden of infectious diseases is high and where research is much needed. Evidence from operational research is vital to attain high-quality healthcare services and achieve universal health coverage [1]. In these contexts research capacity needs to be built rapidly, but models that combine training and implement research at the same time are rare [2].

The SORT IT (Structured Operational Research and Training Initiative) aims to support countries conduct operational research according to their own priorities, build sustainable operational research capacity and enhance evidence-informed decision making to improve public health. Focused on implementers and front-line workers, SORT IT helps to make countries "data rich, information-rich and action-rich" [3].

This issue of JIDC is focused on SORT IT operational research projects from Armenia. It brings together a collection of operational research projects conducted by young researchers from various programmes and that have the potential to contribute to policy and practice.

The JIDC has a genuine commitment to promote operational research in low and middle-income countries. We are encouraged by the enthusiastic response from researchers from these countries and would like to thank all of those who submitted manuscripts and acted as reviewers and associate editors. We are hoping to have a special issue of JIDC for Ukraine as well as Central Asia and Eastern Europe countries and encourage other regions to also contribute to the JIDC.

\section{References}

1. Zachariah R, Guillerm N, Berger S, Kumar AM V., Satyanarayana S, Bissell K, Edginton M, Hinderaker SG, Tayler-Smith K, Van den Bergh R, Khogali M, Manzi M, Reid AJ, Ramsay A, Reeder JC, Harries AD (2014) Research to policy and practice change: is capacity building in operational research delivering the goods? Trop Med Int Health 19: 10681075.

2. Zachariah R, Rust S, Dar Berger S, Guillerm N, Bissell K, Delaunois P, Reid AJ, Kumar AMV V., Olliaro PL, Reeder JC, Harries AD, Ramsay A, Berger SD, Guillerm N, Bissell K, Delaunois P, Reid AJ, Kumar AMV V., Olliaro PL, Reeder JC, Harries AD, Ramsay A, Dar Berger S, Guillerm N, Bissell K, Delaunois P, Reid AJ, Kumar AMV V., Olliaro PL, Reeder JC, Harries AD, Ramsay A (2016) Building global capacity for conducting operational research using the SORT IT model: Where and who? PLoS One 11: e0160837. doi: 10.1371/journal.pone. 0160837

3. Ramsay A, Harries AD, Zachariah R, Bissell K, Hinderaker SG, Edginton M, Enarson DA, Satyanarayana S, Kumar AM V, Hoa NB, Tweya H, Reid AJ, Van den Bergh R, TaylerSmith K, Manzi M, Khogali M, Kizito W, Ali E, Delaunois P, Reeder JC (2014) The Structured Operational Research and Training Initiative for public health programmes. Public Heal Action 4: 79-84.

\section{Corresponding author}

Karapet Davtyan, MD, MPH, MBA

Director of Tuberculosis Research and Prevention Center NGO, Address: Adonts str. 6/2, 115, Yerevan, Armenia, postal code 0014 Tel: 374 -77077793

Email: davkaro@gmail.com

Conflict of interests: No conflict of interests is declared. 